
hronic gastroparesis is a motility dysfunction often associated with severe symptoms, the most common disabling symptoms being nausea and vomiting. The term "gastroparesis" is a Greek word that means "a weakness of movement". In this article, some basic facts about gastroparesis are briefly mentioned before aspects on therapy are discussed.

Gastroparesis is defined as delayed gastric emptying in the absence of an obstruction to outflow from the stomach. Hence, the diagnostic procedure in patients with symptoms suggestive of gastroparesis should include at least gastroscopy, so as to exclude obstructive lesions. Furthermore, a gastric emptying test is required to verify abnormal emptying of the stomach. Although delayed emptying of both liquids and solids occurs in patients with gastroparesis, the delayed emptying of solids is considered the most relevant disturbance. Thus, a test of solid emptying is usually applied. The scintigraphic method is considered to be the gold standard. Reference values based on large control samples (>100 subjects) are available for the scintigraphic method ${ }^{2}$ and for the radiological method. ${ }^{3}$ In addition, the octanoic acid breath test with reference values from 70 subjects $^{4}$ is also frequently used. The larger control samples show a gender difference with a slower emptying rate and higher reference values for retention in healthy women compared with men. ${ }^{2}$ Gastric emptying cannot be reliably evaluated by gastroscopy.

\title{
PATIENT GROUPS
}

In gastrointestinal (GI) practice, gastroparesis is common among patients with diabetes mellitus, and is reported to occur in $30-50 \%$ of the patients. ${ }^{5}$ Another large group comprises patients with idiopathic gastroparesis in whom no underlying cause of the disorder can be found. However, many patients with idiopathic gastroparesis have developed the disorder after a gastrointestinal infection, most often a virus infection. ${ }^{6}{ }^{7}$ Bacterial infections may also cause gastroparesis, but Helicobacter pylori does not seem to be associated with gastroparesis. ${ }^{8}{ }^{9}$ Chronic gastroparesis is also seen to be secondary to systemic disorders such as amyloidosis and scleroderma and to neurological disorders such as Parkinson's disease and myotonic dystrophy. Postsurgical gastroparesis occurs in patients who have undergone ulcer surgery-for example, gastric resections and/or vagotomy. The latter type is likely to become rarer as ulcer surgery decreases, but gastroparesis may also occur after oesophageal surgery such as fundoplication, Heller's myotomy and surgery for oesophageal cancer.

The relation between functional dyspepsia and gastroparesis is of special interest. Delayed gastric emptying is found in about $30 \%$ of patients with functional dyspepsia. ${ }^{10}$ This group of patients with dyspepsia can be regarded as having idiopathic gastroparesis according to the definitions mentioned above.

\section{SYMPTOMS PREDICTIVE OF GASTROPARESIS}

A wide range of dyspeptic symptoms are common in patients with gastroparesis-for example, nausea, vomiting, upper abdominal pain, abdominal distension and bloating. The individual symptoms have, in general, a low specificity to predict delayed emptying. Abdominal bloating has been reported to be significantly correlated with delayed emptying in diabetic gastroparesis. ${ }^{11}$ In other studies, postprandial fullness was statistically linked to delayed gastric emptying. ${ }^{12}{ }^{13}$ When gastroparesis is associated with weight loss and the patient requires nutritional support to maintain body weight, the gastroparesis is considered to be of a more severe form.

Correspondence to: Professor H Abrahamsson, Department of Internal Medicine, Sahlgrenska University Hospital, S-413 45 Göteborg, Sweden; hasse. abrahamsson@medic.gu.se

\section{TRADITIONAL TREATMENT OF GASTROPARESIS}

Before 1990, the medical treatment of gastroparesis included dietary measures such as eating frequent, small, liquid meals with a low fat content. Psychotropic drugs with antiemetic effects were available, although these drugs have no significant prokinetic effect on gastric emptying. During the 1970s and 1980s, dopamine-2 receptor antagonists with antiemetic and some prokinetic effects 
became available (metoclopramide, domperidone). In the 1980s, the 5-hydroxytryptamine 4 (5-HT4) agonist cisapride was marketed and was considered to be a first-line option in drug treatment of gastroparesis. In drug refractory cases, nutritional support via jejunostomy $(\mathrm{J})$-tubes is a possible alternative. In the most advanced cases, gastrectomy has been

878 the final resort, although success with this type of large surgery has been limited.

\section{RECENT ADVANCES IN DRUG TREATMENT}

In the last decade, research has been directed towards obtaining new drugs that can improve gastric emptying and decrease symptoms, without too many side effects. However, despite extensive research, no new drug with proven efficacy in gastroparesis has appeared and been approved during this period.

\section{Macrolides}

Macrolides are a group of substances, some of which have antibiotic properties and/or motilin receptor stimulation action in the GI tract, and thereby exert prokinetic effects. The first macrolide clinically explored was erythromycin, which, in early experiments, showed motility-stimulating properties in dogs. In patients with diabetes mellitus and delayed gastric emptying, Janssens et $a l^{14}$ found that intravenous administration of erythromycin $200 \mathrm{mg}$ before a test meal could normalise the gastric emptying rate of both liquids and solids. After oral administration of erythromycin $250 \mathrm{mg}$ three times a day for 4 weeks, the gastric emptying was improved but not to the same extent as in the initial experiments with intravenous administration. The observations by the Leuven group were confirmed in several studies ${ }^{15}{ }^{16}$ on patients with gastroparesis and also reviewed by Sturm et al. ${ }^{17}$ After long-term administration, the prokinetic effect of erythromycin on gastric emptying may decline due to tolerance development. In clinical practice, treatment with erythromycin in very sick patients is often started at the hospital, with erythromycin given intravenously before the meals. If the patient responds favourably, treatment is then continued with erythromycin suspension given orally in due time, preferably 30-45 min before meals.

Attempts have been made to develop analogues to erythromycin so as to obtain a prokinetic effect without antibiotic effects, and also to overcome the tolerance phenomenon. Although analogues with prokinetic properties have been developed and tested in clinical trials, these drugs have not shown any significant effect on symptoms in patients with delayed gastric emptying. ${ }^{18-20}$ To date, the problem with tolerance development has not been solved and may be one reason why the analogues developed so far do not have the required clinical effects.

Ghrelin is an interesting substance that is structurally related to motilin. Ghrelin is derived from gastric mucosa and seems to have an important role in the regulation of appetite and body weight. Ghrelin has prokinetic motility-stimulating properties in animals, and has also recently been shown to accelerate gastric emptying of a test meal in patients with diabetes with slow gastric emptying. ${ }^{21}$ In patients with idiopathic gastroparesis, ghrelin administration was followed by improved gastric emptying and a decrease in meal-related symptoms. ${ }^{22}$ These interesting effects seen in acute experiments need to be further studied to see if ghrelin-like drugs can be used for treatment of gastroparesis in clinical practice.

The recently developed drugs, mitemcinal and atilmotin, have been proposed as prokinetics, but full papers on their effects in patients with gastroparesis are still lacking.

\section{Dopamine antagonists}

The dopamine-2 (D2) antagonist metoclopramide was developed several decades ago and is still a cornerstone for treatment of gastroparesis in many countries. The prokinetic effects of D2 antagonists in patients with gastroparesis have been thoroughly reviewed ${ }^{17}$ Although metoclopramide has extrapyramidal side effects and sedative effects, at least the latter is not of the same magnitude as that of the older antipsychotic drugs such as haloperidol and chlorpromazine. The D2 antagonist domperidone is an improvement compared with metoclopramide, and has fewer side effects on the central nervous system owing to its limited passage across the blood-brain barrier. Like many other prokinetic drugs, domperidone may show tolerance development on repeated administration, as observed in studies on gastric emptying. ${ }^{23}$ Nevertheless, domperidone is an important alternative in patients in whom gastroparesis-related symptoms respond to dopamine antagonists, but metoclopramide has produced unwanted side effects on the central nervous system.

Sulpiride is a dopamine blocker used for some psychotic and other psychiatric disorders. This drug has prokinetic properties, but a pharmacological profile that is somewhat different from metoclopramide and domperidone, and has been studied in patients with dyspeptic symptoms. The initial studies show that oral levosulpiride $25 \mathrm{mg}$ three times a day is superior to placebo, ${ }^{24}$ and may be as effective as cisapride in relieving nausea and vomiting in patients with gastroparesis. ${ }^{25}{ }^{26}$ Further studies are needed to see whether sulpiride is superior to metoclopramide and domperidone for these gastrointestinal indications.

Itopride is a new D2 antagonist with anti-acetylcholinesterase effects. Itopride has prokinetic properties with promising results in functional dyspepsia, but controlled clinical studies showing its effects in patients with gastroparesis are lacking.

\section{5-HT4 agonists}

As mentioned above, cisapride had for a long time an established place in the treatment of gastroparesis and gastroparesis-related symptoms. ${ }^{17}$ Cisapride is now essentially withdrawn from the market due to cardiac side effects. No other 5-HT4 agonists have shown sufficient effects to be approved for treatment of gastroparesis. The 5-HT4 agonist tegaserod accelerates gastric emptying, ${ }^{27}$ but controlled studies showing significant effects in patients with gastroparesis are still lacking.

\section{Evaluation of frequently used prokinetics}

A systematic analysis by Sturm and co-workers of the effects of the oral prokinetic drugs that are available today and reported on in 36 studies compared the effects of D2 blockers, cisapride and erythromycin. ${ }^{17}$ Erythromycin was found to be the most effective with respect to improvement in gastric emptying compared with metoclopramide, domperidone and cisapride. Erythromycin and domperidone seemed to be the most 


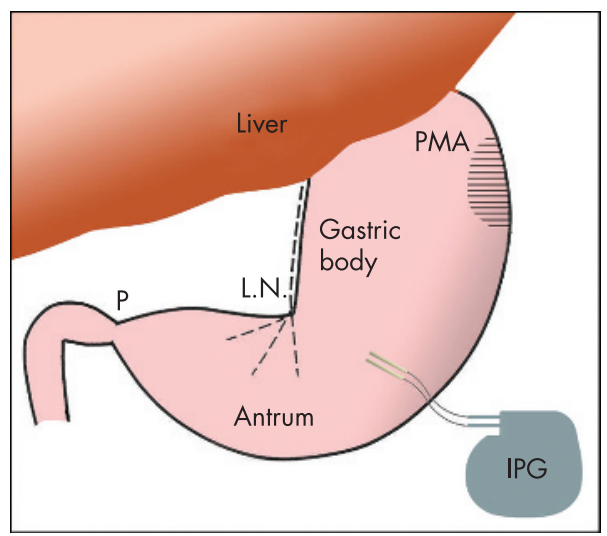

Figure 1 Principle of laparoscopic implantation of electronic device for gastric electrical stimulation (GES) to treat gastroparesis. IPG, impulse generator; LN, Latarjet's nerve with the crow's foot; P, pylorus; PMA, intrinsic gastric pacemaker area.

effective with respect to improvement in gastrointestinal symptom score. There was a lack of association between changes in the gastric emptying rate and improvement in symptoms.

\section{Botulinum toxin}

The use of botulinum toxin (BTX) for treatment of spasm in gastrointestinal sphincters such as the lower oesophageal sphincter (LOS), sphincter of Oddi and the anal sphincter has been followed by attempts to use intrapyloric injections of BTX for the treatment of gastroparesis. The hypothesis was that gastric emptying would be improved if the release of excitatory transmitter substances to the pyloric muscles was inhibited by BTX. This would lead to a decreased resistance to outflow from the stomach in patients with delayed gastric emptying. Injection of BTX at gastroscopy, 100-200 units divided into four portions, has in some small, uncontrolled studies $(<10$ patients) been reported to improve gastric emptying and to decrease symptoms in patients with either idiopathic or diabetic gastroparesis. In a recent retrospective study of 63 patients with gastroparesis, $43 \%$ of the patients experienced symptomatic response to BTX. ${ }^{28}$ The duration of the response was approximately 5 months and improvement was statistically linked to the male gender. To date there has been no controlled study with parallel groups on the effect of BTX in patients with gastroparesis. In a crossover randomised study, preliminarily reported from the Leuven group, ${ }^{29}$ BTX was found not to be superior to a placebo injection with respect to its effects on symptoms and on gastric emptying in 23 patients with predominantly idiopathic gastroparesis. Thus, further studies are needed before the definite value of BTX for treatment of severe gastroparesis can be confirmed.

\section{GASTRIC ELECTRICAL STIMULATION}

The frequency and direction of gastric peristaltic contractions are determined by the underlying gastric electrical slow-wave rhythm. The physiological gastric slow waves are waves of depolarisation (3 waves/min in humans) migrating from the intrinsic pacemaker area in the upper part of the gastric body, from which they move distally towards the pylorus. Studies in dogs showed that with electrical stimulation the peristaltic pressure waves and the gastric emptying rate could be increased by electrical stimulation. ${ }^{30}$ The maximum effect in dogs was found to be at a stimulation rate four times the physiological slow-wave rhythm in the canine stomach. These observations led Abell and co-workers to try gastric electrical stimulation (GES) in a patient with severe diabetic gastroparesis. $^{31}$ In analogy with the animal experiments, this patient received stimulation for $0.1 \mathrm{~s}$ every $5 \mathrm{~s}$ (ie, 12 times/min) and was followed for $>1$ year, and a sustained improvement was noted. The experience from this pilot patient and the stimulation parameters used formed the basis for the following studies on treatment of GES with a fully implantable electronic device. Although the exact mechanism for the antiemetic effect of GES in these studies is unknown, the clinical effect is believed to be mediated by local neurostimulation. The stimulation impulses used $(5 \mathrm{~mA}$, duration $330 \mu \mathrm{s})$ are able to excite nerves but are too weak to excite the gastric smooth muscles-that is, real gastric pacing is not performed. Furthermore, as shown below,

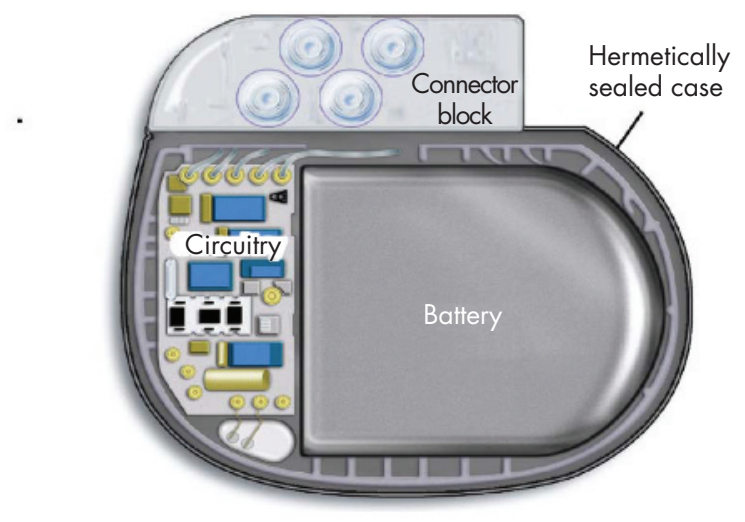

Figure 2 Schematic illustration of the device for gastric electrical stimulation: the impulse generator (Enterra, Medtronic, Minneapolis, Minnesota, USA) and the leads. Two leads are inserted through the gastric serosa with the distal needle so that the uninsulated part of the electrode is located in the muscle layer and kept in place by the anchor and by clips. The leads are connected to the connector block of the impulse generator.

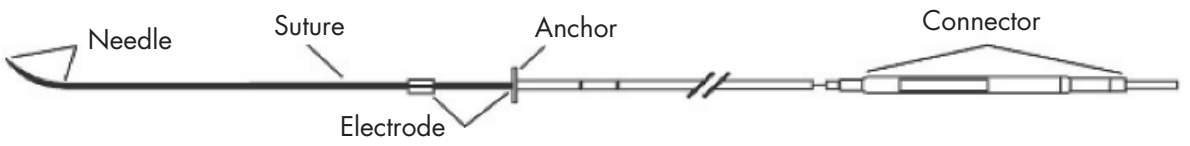




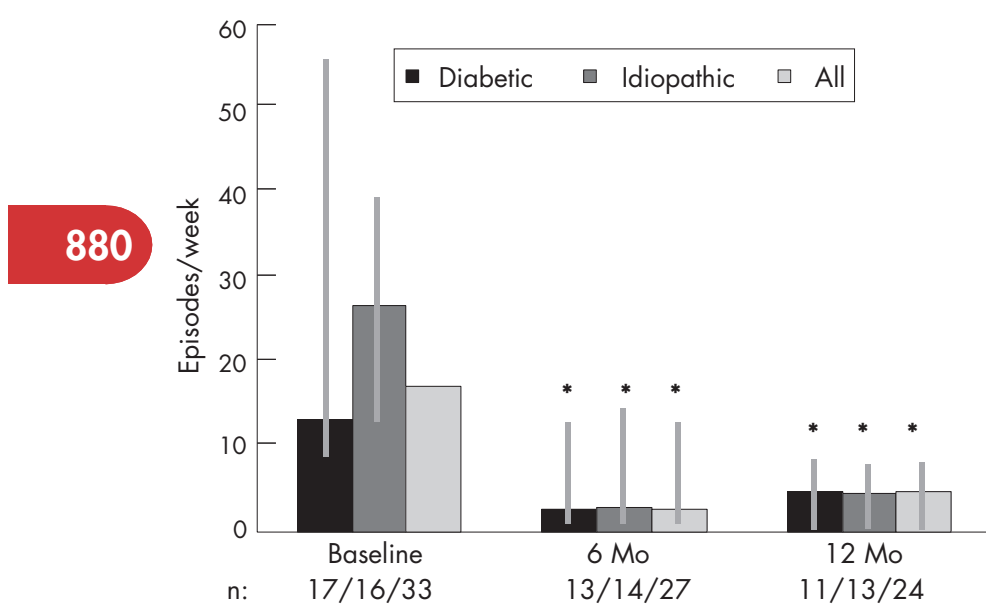

Figure 3 Weekly vomiting frequency (median and interquartile range) at baseline, and changes at 6 and 12 months after the start of gastric electrical stimulation. The number of patients (diabetic, idiopathic, total) is shown below the diagram. ${ }^{*} \mathrm{p}<0.05$ vs baseline. From Abell et al, ${ }^{35}$ with permission from the American Gastroenterological Association.

the primary clinical effect of GES on nausea and vomiting in these studies is not because of an improvement in gastric emptying.

\section{Implantation technique}

The first patients in 1992-4 were implanted by open abdominal surgery. However, in 1995, the laparoscopic implantation technique was introduced by Lönroth ${ }^{32}$ and is now used at most implantation centres (fig 1). The electronic device used so far for treatment of gastroparesis is Enterra (Medtronic, Minneapolis, Minnesota, USA) (fig 2).

The laparoscopic implantation is performed under general anaesthesia with three laparoscopic ports. At laparoscopy, two electrodes are placed anterolaterally in the most proximal part of the antrum approximately $10 \mathrm{~cm}$ from the pylorus (fig 1). We use the crow's foot of Latarjet's nerve as a marker for the level to which electrodes should be inserted into the muscle layer. The technique for laparoscopic placement of electrodes is described in detail elsewhere. ${ }^{32}$ We use the port incision in the left upper quadrant to create a pocket for subcutaneous placement of the impulse generator. The present standard for

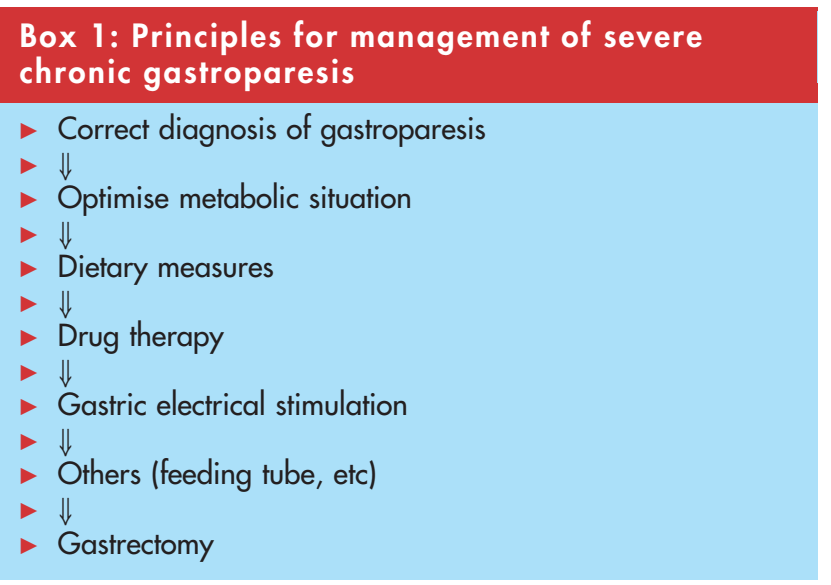

stimulation is based on the observations in the pilot patient, ${ }^{31}$ with two discrete impulses every fifth second and the voltage adjusted to give $5 \mathrm{~mA}$.

If laparoscopy is not possible because of altered intraabdominal anatomy - for example, adhesions - the implantation can be done with laparotomy. The latter technique is a more extensive procedure and needs a longer postoperative hospital stay for most patients. ${ }^{33}$

\section{Clinical results in diabetic and idiopathic gastroparesis} By May $2006>1500$ patients were implanted for treatment with GES with the above-mentioned high-frequency and lowenergy technique. The two largest groups of patients were those with diabetes and idiopathic gastroparesis. Two multicentre trials were published and the patients followed for $\geqslant 12$ months after implantation. In the first study, ${ }^{34}$ the patients received temporary stimulation for 2-4 weeks; the electrodes were implanted by laparoscopy or laparotomy and the battery was placed outside the abdomen. The responding patients were implanted for permanent GES. A sustained effect on nausea and vomiting was noted.

In the second multicentre study, ${ }^{35}$ patients with idiopathic and diabetic gastroparesis were randomised blindly to have stimulation on or off during the first month, and the other mode during the second month. After that the patients underwent GES, with follow-up at 6 and 12 months after implantation. For the initial crossover period the patients' preference for the period with the stimulator on versus off was 3:1 $(\mathrm{p}<0.05)$. During the rest of the study period there was a significant decrease in median vomiting frequency (fig 3 ), in other upper abdominal symptoms and in some of the qualityof-life measures. In the idiopathic gastroparesis group there was a significant decrease in vomiting frequency at 6 and 12 months, but no significant effect on gastric emptying. In these two multicentre studies, the need for antiemetic and prokinetic drugs, nutritional support and hospital stay also decreased with treatment by GES.

Several single-centre studies on patients with idiopathic and diabetic gastroparesis have confirmed these effects of GES on gastroparesis-associated symptoms, and on the need for healthcare, tube feeding and gastric surgery. ${ }^{36-41}$ In some studies but not in all, gastric emptying rate improved with time. The metabolic situation for patients with diabetes, measured as HbAlC, improved in two studies. ${ }^{38} 39$

The most common adverse effect reported in these initial studies ${ }^{34}{ }^{35}$ was device-related infection in approximately $10 \%$ of the patients. The frequency of such infections seems to have decreased during the recent years. This may be explained by a

Box 2: Dietary measures in treatment of gastroparesis

- Restrict meal volumes

- Increase meal frequency

- Small particle meals

- Avoid excess fat

- Avoid excess dietary fibre

- Supplementary nutrition (liquid formula)

- Support by specialised dietician 


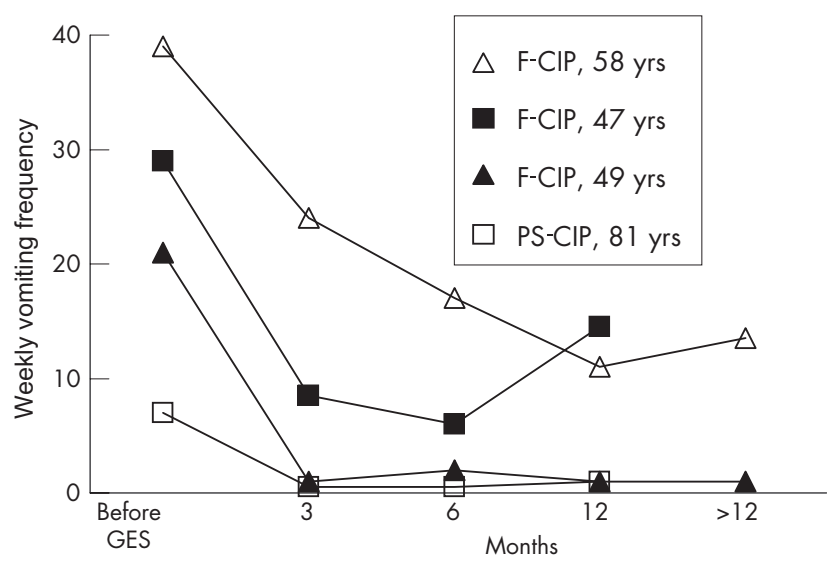

Figure 4 Effect of gastric electrical stimulation on weekly vomiting frequency in four patients with chronic intestinal pseudo-obstruction. For two patients data for $>12$ months (last control) were obtained at 24 and 84 months, respectively. From Andersson et al, ${ }^{44}$ with permission from Blackwell Publishing. F-CIP, familial chronic intestinal pseudo-obstruction; PS-CIP, post surgical chronic intestinal pseudo-obstruction.

more careful surgical technique and the increasing use of laparoscopy instead of open surgery.

\section{New potential indications for GES to treat dyspeptic symptoms}

Recently, patients with various forms of drug refractory postsurgical gastroparesis were also reported to have symptomatic improvement with GES. ${ }^{42}{ }^{43}$ Among 16 patients with gastroparesis $^{42}$ five had symptoms after fundoplication, but patients with a previous partial gastric resection or oesophagectomy were also included. Symptom scores decreased for upper abdominal symptoms but there was no significant effect of GES on gastric emptying in this study. ${ }^{42}$

Chronic intestinal pseudo-obstruction (CIP) has been considered a contraindication for treatment with GES, ${ }^{35}$ even though these patients may suffer from disabling nausea and vomiting. In a small study on four patients with CIP (two of whom had normal gastric emptying tests) nausea and vomiting were found to decrease with GES (fig 4). The improvement was similar to that observed in patients treated with GES for diabetic gastroparesis. ${ }^{44}$

There are also preliminary reports that patients with therapy refractory functional nausea and vomiting but normal gastric emptying may benefit from GES. ${ }^{45-47}$ However, more studies are needed to evaluate the precise role of GES for these new indications.

\section{Cost implications}

GES is a relatively expensive treatment with high costs for the device and for the surgical procedure. The reimbursement principles vary among countries, and in several countries the costs are not yet covered by the healthcare system or insurance companies. In the US the GES device (Enterra, Medtronic) was approved in 2000 by the Food and Drug Administration (Humanitarian Device Exemption) based on the initial multicentre studies. $^{34} 35$

In UK the price of the device by July 2006 was $\$ 13000$ (£6800 ex VAT) and for the whole procedure was approximately
Box 3: Drug therapy in gastroparesis

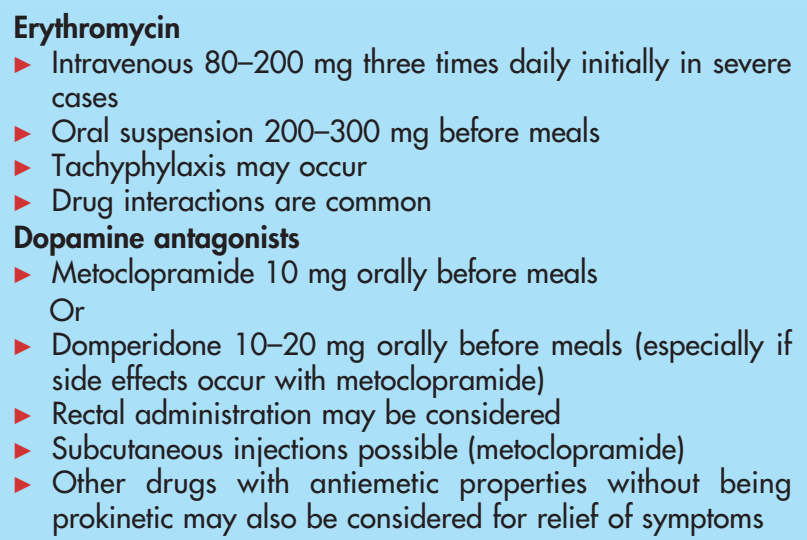

$\$ 36300$ ( $£ 19$ 000) (Fullarton, personal communication). In the US, at the Jackson Centre, the price of the device for the patient was $\$ 17000$ and surgery added another $\$ 25000$, thus totalling $\$ 42000$ (Abell, personal communication). On average, the total price in the US is between $\$ 40000$ and $\$ 60000$, but a price of up to $\$ 100000$ does occur (Bulger, Medtronic, personal communication). In Scandinavia, the price of the device is about $\$ 11$ 500-12 500, and for the whole procedure the price in Sweden is $\$ 28000$ (SEK 200 000).

There are few studies on the healthcare benefits of GES compared with conventional treatment of patients with very severe gastroparesis. Abell and colleagues performed a detailed study over 3 years of two small patient groups with a comparable symptom burden at baseline. ${ }^{48}$ Compared with a group included in an intensive treatment programme with pharmaceutical drugs, the patient group receiving GES had more improved symptoms and had a significantly lower consumption of healthcare resources during the study period.

\section{The responder/non-responder issue}

GES is an advanced but relatively expensive therapy. Focus has recently been directed to the problem of a proportion of patients not responding to GES. In the early multicentre study by Abell et $a l,{ }^{35} 24$ of the initial 33 patients remained in the study after 12 months (fig 3) and could be evaluated. The overall proportion of non-responders, having $<25 \%$ symptom reduction, was $13 \%$. However, recent reports on larger patient materials indicate a higher non-response rate to GES in idiopathic gastroparesis. In the Kansas City sample of 87 patients with therapy refractory gastroparesis, 35\% of the idiopathic patients were non-responders after 12 months compared with $10 \%$ in the diabetic group and $17 \%$ in postsurgical gastroparesis. ${ }^{49}$ Similarly, a high proportion of non-responders, 50\%, was reported from the Philadelphia group, particularly for the idiopathic patients. ${ }^{50}$ The latter group also included patients with gastroparesis with pain as the main symptom, and this subset of patients had a low response rate to GES. Some patients may respond to an increase in stimulation strength and frequency. ${ }^{51}$ So far, the impression is that various preoperative clinical parameters are only weak predictors of the response to GES. ${ }^{49}{ }^{50}$ Thus, there is a definite need for direct tests that can predict the symptomatic response to GES. 
Abell and colleagues have applied temporary GES with endoscopically placed electrodes (predominantly the oral route) and used the effects on symptoms after $\geqslant 3$ days as a measure of response..$^{52}$

Another approach to test response to temporary GES is to implant gastric electrodes percutaneously under gastroscopic assistance..$^{53}$ With this simple percutaneous technique, temporary GES has been tested in patients for up to 2 months. ${ }^{46}$ Thus, "double-blind" crossover testing of GES can be performed and responders/non-responders to GES can be selected. ${ }^{46}$ This principle to test the effects of GES seems promising and may help minimise the clinical problem with permanent implants to non-responders, and may be helpful in studying the effect of GES on new potential patient groups. ${ }^{46}$

\section{Comments}

The introduction of GES seems to be a clear step forward in the treatment of many patients with previous drug-refractory gastroparesis. Several issues related to GES remain to be resolved. One important aspect is that the mechanism of action for the effect of GES on gastroparesis-related symptoms is not yet known. The primary action does not seem to be an improvement in gastric emptying because marked symptom improvement can occur without any effect on emptying. ${ }^{34-36}$ In most studies, an effect on emptying, if it exists at all, seems to appear a considerable time after symptom improvement. The improvement in gastric emptying with time in some studies may be related to the improved nutritional status of the patients or may be secondary to the decrease in nausea. Further research is required to find out the optimal stimulation parameters with respect to stimulation frequency and strength. Moreover, the optimal site for electrode placement should be further studied.

\section{STRATEGY FOR TREATMENT OF SEVERE GASTROPARESIS IN CLINICAL PRACTICE}

Based on the various treatment options described above, some general principles can be applied as outlined in box 1. For patients with diabetic gastroparesis, it is of special importance to take the metabolic situation into consideration. Hyperglycaemia is known to delay gastric emptying and to attenuate the effects of prokinetic drugs on gastric emptying, ${ }^{54-59}$ and should be optimised in patients with diabetes mellitus. With respect to HbAlc, no consistent effect of prokinetic treatment with cisapride on the metabolic situation has been reported ${ }^{60}{ }^{61}$ but sulpiride had a significant effect according to one report. ${ }^{62}$

\section{Dietary management}

The dietary recommendations (box 2) are widely used and mainly based on knowledge of the pathophysiology of gastroparesis, often with weak peristaltic contractions and reduced accommodation to meal volumes. All recommendations have not been separately studied and proven. ${ }^{63}$ In principle, the diet usually recommended for patients with diabetes mellitus can be recommended also for patients with diabetic gastroparesis or gastroparesis of other aetiology. To decrease fat energy below $30 \%$ probably adds little further benefit. The meal particle size should be kept small, as particles $\geqslant 2 \mathrm{~mm}$ tend to empty slowly. The grinding capacity is often low in the affected stomach. In our experience, a dietician with expertise in gastroparesis is a good support for the patients.

\section{Pharmacological treatment}

In practice the cornerstones of drug therapy are essentially the same as 10 years ago, except that the use of cisapride has been strongly restricted or abandoned (box 3). Both D2 receptor antagonists and erythromycin should be tested before the patient is categorised as drug refractory. Domperidone is not available in all countries. The role of BTX is unclear and, at present, at least the long-term effect of BTX seems to be limited.

\section{Medically refractory gastroparesis}

The experience with GES in the last decade indicates that it is an option which should be considered for patients with severe symptoms and refractory to the above-mentioned treatment steps. GES seems to have decreased the need for feeding tubes and for gastric resection surgery. Therefore, this minimal invasive surgery method is now an option for patients otherwise requiring the older tube and/or gastrectomy procedures.

Competing interests: None.

\section{REFERENCES}

1 Tougas G, Eaker E, Abell T, et al. Assessment of gastric emptying using a low fat meal: establishment of international control values. Am J Gastroenterol 2000:95: 1456-62.

2 Grybäck P, Hermansson G, Lyrenäs $E$, et al. Nationwide standardisation and evaluation of scintigraphic gastric emptying: reference values and comparisons between subgroups in a multicentre trial. Eur J Nucl Med 2000;27:647-55.

3 Strid H, Simrén M, Stotzer P-O, et al. Delay in gastric emptying in patients with chronic renal failure. Scand J Gastroenterol 2004;39:516-20.

4 Maes BD, Ghoos YF, Hiele MI, et al. Gastric emptying rate of solids in patients with nonulcer dyspepsia. Dig Dis Sci 1997;42:1158-62.

5 Horowitz M, Wishart JM, Jones KL, et al. Gastric emptying in diabetes: an overview. Diabet Med 1996;13(Suppl 5):S16-22.

6 Bityutskiy LP, Soykan I, McCallum RW. Viral gastroparesis: a subgroup of idiopathic gastroparesis - clinical characteristics and long-term outcomes. Am J Gastroenterol 1997:92:1501-4.

7 Soykan I, Sivri B, Sarosiek I, et al. Demography, clinical characteristics, psychological and abuse profiles, treatment, and long-term follow-up of patients with gastroparesis. Dig Dis Sci 1998;43:2398-404.

8 Caballero-Plasencia AM, Muros-Navarro MC, Martin-Ruiz JL, et al. Dyspeptic symptoms and gastric emptying of solids in patients with functional dyspepsia. Role of Helicobacter pylori infection. Scand J Gastroenterol 1995;30:745-51.

9 Schoonjans R, Van VB, Vandamme W, et al. Dyspepsia and gastroparesis in chronic renal failure: the role of Helicobacter pylori. Clin Nephrol 2002;57:201-7.

10 Tack J, Bisschops R, Sarnelli G. Pathophysiology and treatment of functional dyspepsia. Gastroenterology 2004;12:1239-55.

11 Jones KL, Russo A, Stevens JE, et al. Predictors of delayed gastric emptying in diabetes. Diabetes Care 2001;24:1264-9.

12 Stanghellini V, Tosetti C, Paternic A, et al. Risk indicators of delayed gastric emptying of solids in patients with functional dyspepsia. Gastroenterology 1996; 110:1036-42.

13 Sarnelli G, Caenepeel P, Geypens B, et al. Symptoms associated with impaired gastric emptying of solids and liquids in functional dyspepsia. Am J Gastroenterol 2003:98:783-8.

14 Janssens J, Peeters TL, Vantrappen G, et al. Improvement of gastric emptying in diabetic gastroparesis by erythromycin. Preliminary studies. N Engl J Med 1990;322:1028-31.

15 Richards RD, Davenport K, McCallum RW. The treatment of idiopathic and diabetic gastroparesis with acute intravenous and chronic oral erythromycin. Am J Gastroenterol 1993;88:203-7.

16 Camilleri $M$. The current role of erythromycin in the clinical management of gastric emptying disorders. Am J Gastroenterol 1993;88:169-71.

17 Sturm A, Holtmann G, Goebell H, et al. Prokinetics in patients with gastroparesis: a systematic analysis. Digestion 1999;60:422-7.

18 Talley NJ, Verlinden M, Snape W, et al. Failure of a motilin receptor agonist (ABT-229) to relieve the symptoms of functional dyspepsia in patients with and without delayed gastric emptying: a randomized double-blind placebocontrolled trial. Aliment Pharmacol Ther 2000;14:1653-61.

19 Talley NJ, Verlinden M, Geenen DJ, et al. Effects of a motilin receptor agonist (ABT-229) on upper gastrointestinal symptoms in type 1 diabetes mellitus: a randomised, double blind, placebo controlled trial. Gut 2001;49:395-401.

20 Russo A, Stevens JE, Giles N, et al. Effect of the motilin agonist KC 11458 on gastric emptying in diabetic gastroparesis. Aliment Pharmacol Ther 2004;20:333-8. 
21 Murray CD, Martin NM, Patterson M, et al. Ghrelin enhances gastric emptying in diabetic gastroparesis: a double blind, placebo controlled, crossover study. Gut 2005; 54:1693-8.

22 Tack J, Depoortere I, Bisschops R, et al. Influence of ghrelin on gastric emptying and meal-related symptoms in idiopathic gastroparesis. Aliment Pharmacol The 2005;22:847-53.

23 Horowitz M, Harding PE, Chatterton BE, et al. Acute and chronic effects of domperidone on gastric emptying in diabetic autonomic neuropathy. Dig Dis Sci 1985;30:1-9.

24 Mansi C, Savarino V, Vigneri S, et al. Gastrokinetic effects of levosulpiride in dyspeptic patients with diabetic gastroparesis. Am J Gastroenterol 1995:90:1989-93.

25 Mansi C, Borro P, Giacomini M, et al. Comparative effects of levosulpiride and cisapride on gastric emptying and symptoms in patients with functional dyspepsia and gastroparesis. Aliment Pharmacol Ther 2000;14:561-9.

26 Mearin F, Rodrigo L, Perez-Mota A, et al. Levosulpiride and cisapride in the treatment of dysmotility-like functional dyspepsia: a randomized, double-masked trial. Clin Gastroenterol Hepatol 2004;2:301-8.

27 Degen $L$, Petrig C, Studer D, et al. Effect of tegaserod on gut transit in male and female subjects. Neurogastroenterol Motil 2005;17:821-6.

28 Bromer MQ, Friedenberg F, Miller LS, et al. Endoscopic pyloric injection of botulinum toxin A for the treatment of refractory gastroparesis. Gastrointest Endosc 2005;61:833-9.

29 Arts J, Caenepeel P, Holvoet L, et al. A sham-controlled study of intrapyloric injection of botulinum toxin in gastroparesis. Gastroenterology 2005;128(Suppl 2):A-81.

30 Familione B, Abell T, Nemoto D, et al. Efficacy of electrical stimulation at frequencies higher than basal rate in canine stomach. Dig Dis Sci 1997;42:892-7.

31 Familione B, Abell T, Voeller G, et al. Electrical stimulation at a frequency higher than basal rate in human stomach. Dig Dis Sci 1997:42:885-91.

32 Lönroth H, Abrahamsson H. Laparoscopic and open placement of electronic implants for gastric electrical stimulation: technique and results. Minim Invasive Ther Allied Technol 2004;13:336-9.

33 Al-Juburi A, Granger S, Barnes J, et al. Laparoscopy shortens length of stay in patients with gastric electrical stimulators. I Soc Laparoendosc Surg 2005;9:305-10.

34 Abell T, Van Cutsem E, Abrahamsson H, et al. Gastric electrical stimulation in intractable symptomatic gastroparesis. Digestion 2002;66:204-12.

35 Abell T, McCallum R, Hocking $M$, et al. Gastric electrical stimulation for medically refractory gastroparesis. Gastroenterology 2003;125:421-8.

36 Forster J, Sarosiek I, Lin Z, et al. Further experience with gastric stimulation to treat drug refractory gastroparesis. Am J Surg 2003;186:690-5.

37 Abell T, Lou J, Tabbaa M, et al. Gastric electrical stimulation for gastroparesis improves nutritional parameters at short, intermediate, and long-term follow-up. J Parenter Enteral Nutr 2003;27:277-81.

38 Lin Z, Forster J, Sarosiek I, et al. Treatment of diabetic gastroparesis by highfrequency gastric electrical stimulation. Diabetes Care 2004;27:1071-6.

39 van der Voort IR, Becker JC, Dietl KH, et al. Gastric electrical stimulation results in improved metabolic control in diabetic patients suffering from gastroparesis. Exp Clin Endocrinol Diabetes 2005;113:38-42.

40 Lin Z, McElhinney C, Sarosiek I, et al. Chronic gastric electrical stimulation for gastroparesis reduces the use of prokinetic and/or antiemetic medications and the need for hospitalizations. Dig Dis Sci 2005;50:1328-34.

41 Mason RJ, Lipham J, Eckerling G, et al. Gastric electrical stimulation: an alternative surgical therapy for patients with gastroparesis. Arch Surg 2005; 140:841-6

42 McCallum R, Lin Z, Wetzel $P$, et al. Clinical response to gastric electrical stimulation in patients with postsurgical gastroparesis. Clin Gastroenterol Hepatol 2005;3:49-54

43 Oubre B, Luo J, Al-Juburi A, et al. Pilot study on gastric electrical stimulation on surgery-associated gastroparesis: long-term outcome. South Med J 2005;98:693-7.
44 Andersson S, Lönroth H, Simren M, et al. Gastric electrical stimulation for intractable vomiting in patients with chronic intestinal pseudoobstruction. Neurogastroenterol Motil 2006;18:823-30.

45 McCallum RW, Lin Z, Sarosiek I, et al. Is high-frequency gastric electrical stimulation effective in patients with chronic nausea and vomiting and a normal gastric emptying? Gastroenterology 2006;130(Suppl 2):A-511.

46 Abrahamsson H, Andersson S, Ringström G, et al. Temporary percutaneous gastric electrical stimulation (GES). A new technique to test response to GES Neurogastroenterol Motil 2006;18:668.

47 Gourcerol G, Leblanc I, Leroi AM, et al. Gastric electrical stimulation in medically refractory nausea and vomiting. Neurogastroenterol Motil 2006;18:741.

48 Cutts TF, Luo J, Starkebaum W, et al. Is gastric electrical stimulation superior to standard pharmacologic therapy in improving $\mathrm{Gl}$ symptoms, healthcare resources, and long-term health care benefits? Neurogastroenterol Motil 2005; 17:35-43.

49 Lin Z, Sarosiek I, Forster J, et al. Predictors of symptom non-responders to highfrequency gastric electrical stimulation for refractory gastroparesis. Gastroenterology 2006;130(Suppl 2):A-246.

50 Maranki JL, Lytes V, Merilahn JE, et al. Predictive factors for clinical improvement with Enterra gastric electrical stimulation treatment for refractory gastroparesis. Gastroenterology 2006;130(Suppl 2):A-43.

51 Abidi N, Starkebaum WL, Abell TL. An energy algorithm improves symptoms in some patients with gastroparesis and treated with gastric electrical stimulation. Neurogastroenterol Motil 2006; 18:334-8.

52 Ayinala S, Batista O, Goyal A, et al. Temporary gastric electrical stimulation with orally or PEG-placed electrodes in patients with drug refractory gastroparesis. Gastrointest Endosc 2005;61:455-61.

53 Elfvin A, Andersson S, Abrahamsson $\mathrm{H}$, et al. Percutaneous implantation of gastric electrodes - a novel technique applied in animals and in patients. Neurogastroenterol Motil 2007;19:103-9.

54 Petrakis IE, Vrachassotakis N, Sciacca V, et al. Hyperglycaemia attenuates erythromycin-induced acceleration of solid-phase gastric emptying in idiopathic and diabetic gastroparesis. Scand J Gastroenterol 1999;34:396-403.

55 Jones KL, Berry M, Kong MF, et al. Hyperglycemia attenuates the gastrokinetic effect of erythromycin and affects the perception of postprandial hunger in normal subjects. Diabetes Care 1999;22:339-44.

56 Rayner CK, Su YC, Doran SM, et al. The stimulation of antral motility by erythromycin is attenuated by hyperglycemia. Am J Gastroenterol 2000;95:2233-41.

57 Petrakis IE, Kogerakis N, Prokopakis G, et al. Hyperglycemia attenuates erythromycin-induced acceleration of liquid-phase gastric emptying of hypertonic liquids in healthy subjects. Dig Dis Sci 2002;47:67-72.

58 Horowitz M, Jones KL, Harding PE, et al. Relationship between the effects of cisapride on gastric emptying and plasma glucose concentrations in diabetic gastroparesis. Digestion 2002;65:41-6.

59 Petrakis IE, Kogerakis N, Vrachassotakis N, et al. Hyperglycemia attenuates erythromycin-induced acceleration of solid-phase gastric emptying in healthy subjects. Abdom Imaging 2002;27:309-14.

60 Braden B, Enghofer M, Schaub M, et al. Long-term cisapride treatment improves diabetic gastroparesis but not glycaemic control. Aliment Pharmacol Ther 2002;16:1341-6.

61 Lehmann R, Honegger RA, Feinle C, et al. Glucose control is not improved by accelerating gastric emptying in patients with type 1 diabetes mellitus and gastroparesis. A pilot study with cisapride as a model drug. Exp Clin Endocrinol Diabetes 2003;111:255-61.

62 Melga P, Mansi C, Ciuchi E, et al. Chronic administration of levosulpiride and glycemic control in IDDM patients with gastroparesis. Diabetes Care 1997:20:55-8.

63 Gentilcore D, O'Donovan D, Jones KL, et al. Nutrition therapy for diabetic gastroparesis. Curr Diabetes Rep 2003;3:418-26. 